\title{
2017 AWARDS
}

\section{Agri-King Outstanding Animal Science Graduate Student Award}

Jordan M. Thomas

University of Missouri

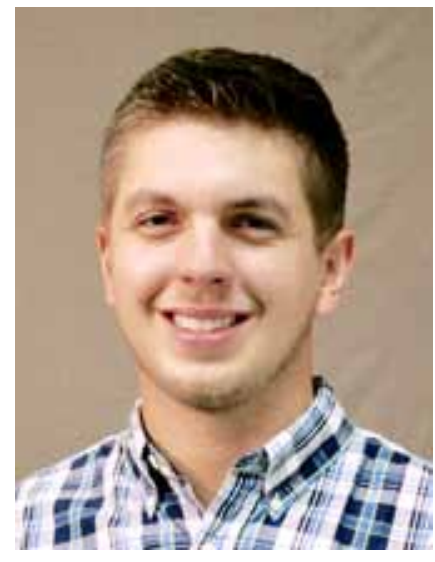

Jordan M. Thomas completed his Master of Science degree in Animal Science at the University of Missouri and will ful 11 requirements for his $\mathrm{PhD}$ at University of Missouri in August of this year. e focus of Jordan's research has led to the development of novel strategies to optimize ovulation synchronization for expanded use of sex sorted semen; accomplishments which highlight his scientific ingenuity and scholarly understanding of fundamental reproductive biology. e extent of his research efforts as a graduate student are unparalleled by his peers. To date, Thomas has coordinated experiments involving a total of over 13,000 animals in 17 locations across seven states. Jordan's research efforts resulted or contributed to 11 peer- reviewed publications, 26 scientific abstracts and 10 proceedings papers for national meetings, one University of Missouri Extension publication, one book chapter, and 45 invited presentations at regional, national, and international forums.

\section{AFIA - Nonruminant Nutrition Research \\ Dr. Sung Woo Kim North Carolina State University}

Since graduation with the $\mathrm{Ph} . \mathrm{D}$. degree from the University of Illinois in 1999, Dr. Sung Woo Kim has developed a world-class and productive research program in pig nutrition. e results of his outstanding research have significantly advanced our knowledge about utilization of protein, amino acids, and other nutrients in growing- finishing, gestating, and lactating swine. Dr. Kim is currently a Professor of Nutrition at North Carolina State University. Together with his graduate students, visiting scholars, and collaborators, he has published 153 peer reviewed papers, 17 book chapters, and given 172 invited talks in 22 countries. In recognition of his seminal contributions to swine nutrition, Dr.

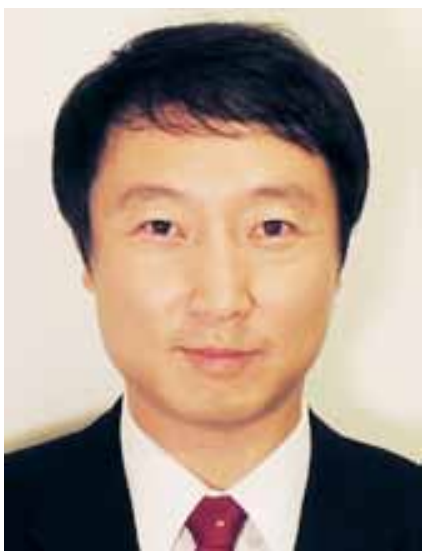
Kim has received the Early Career Achievement Award and Outstanding Young Scientist Award from the American Society of Animal Science, e Vernon Young International Award for Amino Acid Research from the American Society of Nutrition, and Outstanding Research Award from the Asian Animal Science.

\section{AFIA - Ruminant Nutrition Research Dr. Luis O. Tedeschi Texas A\&M University}

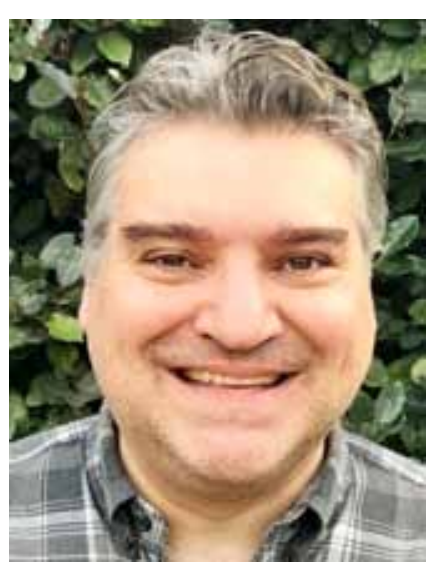

Dr. Luis Tedeschi received his bachelor's degree in Agronomy Engineering from the University of São Paulo (USP-Brazil) in 1991, his master's degree in Animal and Forage Sciences from the USP in 1996, and his doctorate in Animal Science from Cornell University (NY) in 2001. Following a

Research Associate position at Cornell University from 2002 to 2005, he joined Texas A\&M University in 2005 and was promoted to professor in 2015. Dr. Tedeschi teaches ruminant nutrition, precision diet formulation, comparative ruminant production, and modeling courses for undergraduate and graduate students. His internationally recognized research pro- 
gram is focused on the integration of mathematical nutrition modeling and scientific data from research trials conducted at his own laboratory, as well as many universities and research institutes around the world. He has published more than 200 papers in peer-reviewed journals and book chapters, and presented at more than 85 conferences and workshops worldwide.

\section{Animal Growth and Develop Award Dr. Min Du Washington State University}

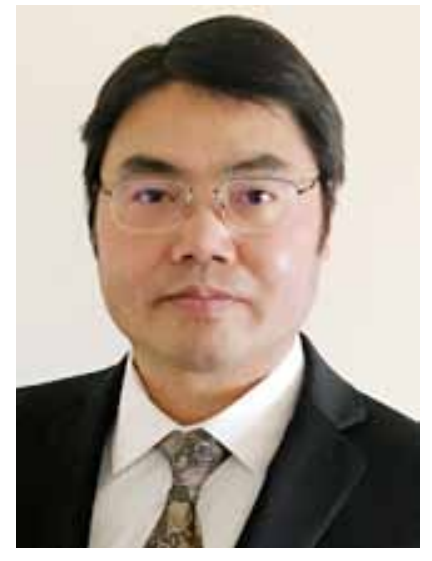

Dr. Min Du earned his B.S. from Zhejiang University, M.S. from China Agricultural University and Ph.D. from Iowa State University. A er postdoctoral training at the University of Alberta, he was an Assistant Professor and then an Associate Professor at the University of Wyoming. In 2011, he moved to Washington State University as a Professor and Endowed (Funded) Chair. His research focuses on stem cell differentiation and muscle and adipose tissue development, and is well funded by USDA and NIH awards (greater than $\$ 22$ million). Dr. Du has trained more than 30 graduate students and postdoctoral scholars and published 194 peer-reviewed articles and is a frequent speaker for national/international meetings. He was an Associate Editor for the Journal of Animal Science, and is a reviewer or panel member for more than 40 scientific journals and funding agencies. He was the recipient of the Young Scientist Award, Early Career Achievement Award from ASAS, and UW Outstanding Advisor Award.

\section{Animal Industry Service Award \\ Dr. Darrh K. Bullock \\ University of Kentucky}

Dr. Darrh Bullock was raised on a commercial cow/calf and watermelon family farm in Williston, Florida. He earned a BS and MS from Auburn University and his $\mathrm{PhD}$ in Animal Breeding and Genetics from the University of Georgia. Dr. Bullock began his career at the University

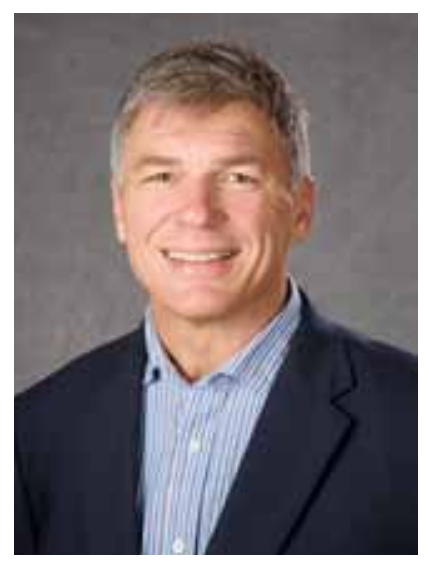
of Kentucky in 1992 and coordinates the beef breeding and genetic management educational activities in Kentucky. Darrh's Extension programs have had impacts across the US primarily in beef cattle genetics. He has developed educational materials for cattlemen across the country through his work with the Beef Improvement Federation, National Beef Cattle Evaluation Consortium and eBEEF.org. Ten thousand copies of the NBCEC Sire Selection Manual, that he coordinated and co-authored, have been distributed. He has been invited to speak in 22 states and abroad. Darrh received the 2015 ASAS Extension Award. Darrh and his wife, Helene, have two adult children, Lukas and Hanna.

\section{Animal Management Award \\ Dr. Rick N. Funston University of Nebraska-Lincoln}

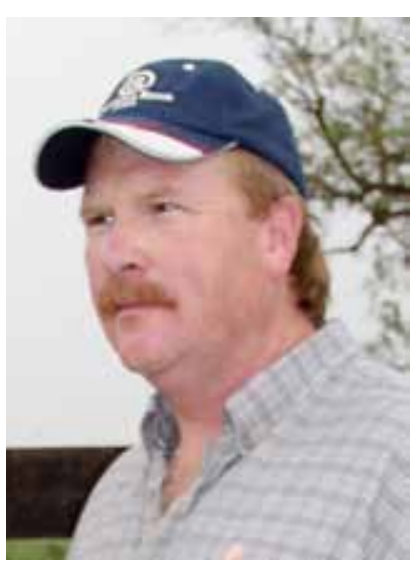

Dr. Rick Funston has established a state, national and international reputation in the area of beef systems/ heifer management systems. He has an international reputation for his groundbreaking research in reproductive management and fetal programming. 
Funston has taught beef producers how to capitalize on resource and market opportunities to add new pro $t$ centers to their ranch business to increase ranch profits. Funston's leadership, scholarly accomplishments, program impacts, communication skills and his program visibility are well documented. His ability to seamlessly combine his extension and research programs has become a model for state specialists nationally. His research is at the cutting edge of science and is being confirmed by numerous researchers around the country. Funston has the unique ability to translate his research into management.

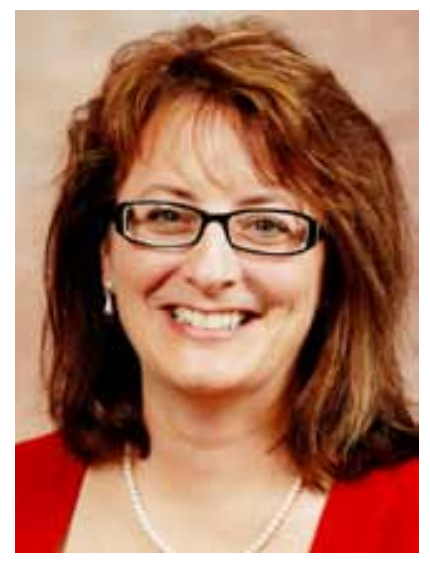

\section{Animal Physiology and Endocrinology Award}

\section{Dr. Andrea S. Cupp University of Nebras- ka-Lincoln}

Dr. Andrea Cupp
is a Professor in
the Department of Animal Science at the University of Nebraska. She received her BS from Virginia Tech and her $\mathrm{MS}$ and $\mathrm{PhD}$ from the University of Nebraska. She completed postdoctoral training in Cellular and Molecular Endocrinology at the University of California-San Francisco and Washington State. She held positions of Research Assistant Professor and Director of the Transgenic \& Knockout mouse facility within the Center of Reproductive Biology at Washington State before joining the Animal Science Department at Nebraska as an Assistant Professor in 2000. Since then she has been promoted to Associate and then to Full Professor. In 2015, in recognition of her achievements, she was appointed to the Omtvedt Endowed Professorship. Cupp is a highly respected scientist and teacher with a notable program in reproductive biology. She has excelled in all three pillars of the land-grant missions and has earned international recognition for her accomplishments.

\section{ASAS President's Award for International Achievements in Animal Science \\ Dr. Rupert Bruckmaier University of Bern}

Dr. Bruckmaier has been working on the physiology and endocrinology of lactating ruminants. His work contributed significantly to the knowledge in the eld of milking physiology and the importance of oxytocin and other hormones in the regulation of milk ejection. e work from his group also contributed significantly to understanding the mammary immune response, including pathogen-specifc differences of activation of different components of the immune system, thus explaining differences in the course of mastitis a er infection with different pathogens. His studies on the metabolism of high yielding dairy cows have shown an individually different adaptive capacity to metabolic load as a potential basis for animal breeding, but also a different endocrine adaptation to nutrient deficiency at different stages of lactation. During all research activities he has tried to support young scientists in the development of their future careers.

\section{Bouffault International Animal Agriculture Award

\author{
Dr. Curtis R. Youngs
} \\ Iowa State University}

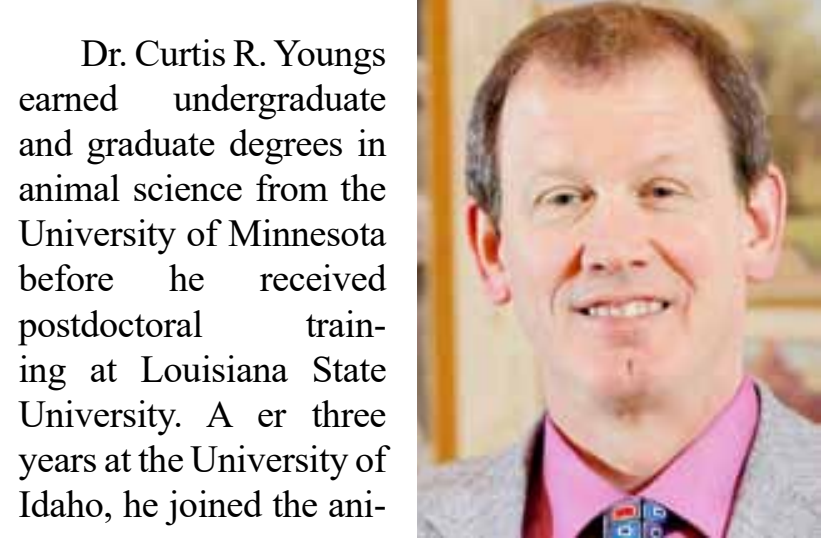


mal science faculty at Iowa State University. He has utilized his expertise to train scientists and students in developing countries in the technologies of artificial insemination and embryo transfer. He brought the unique courses he created in embryo transfer and in global food security to countries that greatly needed enhanced production of animal source foods. Youngs' development work has been performed in nine developing countries across four continents, and his activities have included classroom and laboratory teaching, on-farm consultations, and research. He hopes to empower agriculturalists in developing nations with the knowledge and skills needed to increase production of safe and nutritious animal source foods.

\section{Corbin Award in Companion Animal Biology \\ Dr. Lisa K. Karr Univeristy of Nebraska-Lincoln}

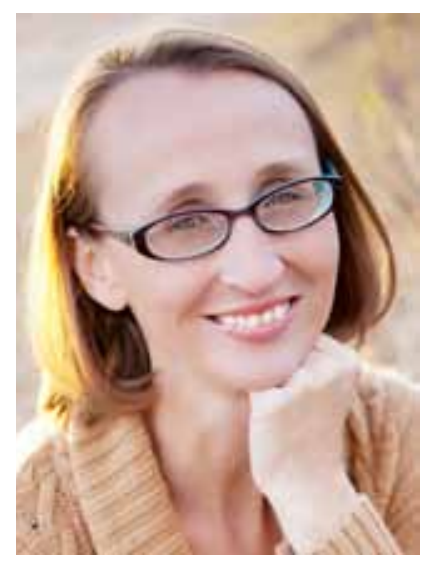

Dr. Lisa Karr is an Associate Professor of Animal Science at the University of NebraskaLincoln. An awardwinning teacher and adviser, she has authored 30 peer- reviewed research publications, two book chapters, and 75 extension publications. Lisa is active in the companion animal extension community at the national level, primarily through her involvement as Chair of eXtension.org's Companion Animal Community of Practice Leadership Committee. She has given 25 presentations or proceedings at local and national conferences and meetings over the span of her career. Dr. Karr's work is sure to have a lasting impact on the companion animal landscape through her education of the eld's future scientists and national dissemination of extension best practices.

\section{Distinguished Teacher Award \\ Dr. William L. Flowers \\ North Carolina State University}

Dr. William L. Flowers has excelled in teaching during the past 30 years. He has taught over 5,000 students and consistently ranks in the top $1 \%$ of all teachers at NCSU. He has mentored 246 undergraduate students in teaching/ research projects, 82 of which have completed advanced degrees and now have positions in academia, industry, or government. Each of the top 25 swine producers in the world have his students in key positions. He is a co-founder of the first lateral entry program in the US for food animal veterinarians (Food Animal Scholars) and the first distance education program for swine management professionals (Swine On-Line). He has secured over \$2 million in support of his teaching programs including \$1 million in industry donations of new technologies for use in his advanced courses. He has 178 peer-reviewed publications of which 64 are directly related to teaching. He resides in Apex, N.C. with his wife, Lynn; son, AJ; and a menagerie of animals.

\section{ASAS Early Career Achievement Award \\ Dr. Greg B. Penner University of Saskatchewan}

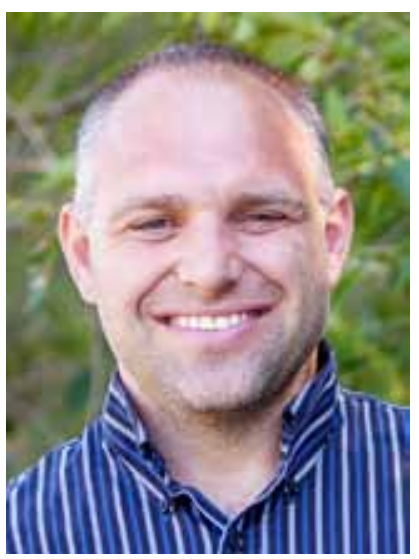

Dr. Greg Penner is a recognized leader in the eld of ruminant nutrition, in particular addressing issues related to acidosis, volatile fatty acid absorption and functionality of the gastrointestinal tract. Greg joined the Department of Animal and Poultry Science, University of Saskatchewan (Canada) 
in 2009 as an Assistant Professor of Ruminant Nutritional Physiology. Five years later he was promoted to Associate Professor with tenure and in 2014 he was appointed Centennial Enhancement Chair in Ruminant Nutritional Physiology at the University of Saskatchewan. Greg grew up on the family farm in Saskatchewan which inspired his curiosity in animal science. He attended the University of Saskatchewan where he received his BSc Agr. in 2004 and his MSc in 2006. Greg then obtained his Ph.D. from the University of Alberta in 2009. Dr. Greg Penner has in a short period of time demonstrated excellence in ruminant nutrition research, teaching, and extension.

\section{ASAS Early Career Achievement Award \\ Dr. Ryan N. Dilger \\ University of Illinois - Urbana-Champaign}

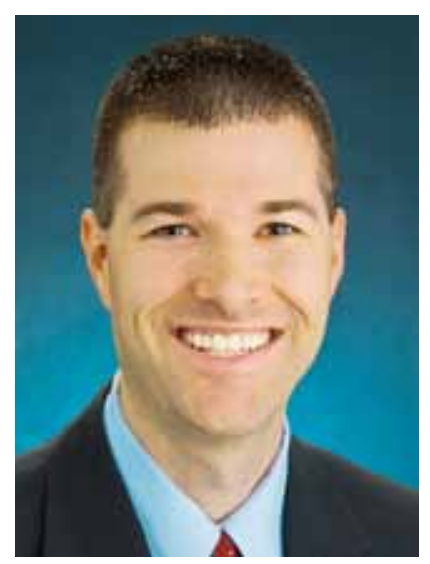

Dr. Ryan Dilger is an Associate Professor at the University of Illinois Urbana- Champaign campus where he studies the interaction of nutrition, immunology, and neuroscience. $\mathrm{He}$ received his B.S and M.S degrees at Purdue University, and completed his Ph.D. at the University of Illinois under the direction of Dr. David H. Baker. Ryan went on to complete post doctorate research with Dr. Rodney Johnson at the same institution before joining the University of Illinois faculty in 2010. Overall, his research projects can be broadly categorized into two areas: 1) practical nutrition and health issues facing production animal agriculture, and 2) fundamental nutrition and developmental questions studied using the pig as a translational model to improve human health and well-being. Dr. Dilger has published 65 peer-reviewed articles and generated $\$ 9.6$ million in research funding since starting on faculty in 2010.

\section{ASAS Early Career Achievement Award

\author{
Dr. Stephanie L. Hansen \\ Iowa State University
}

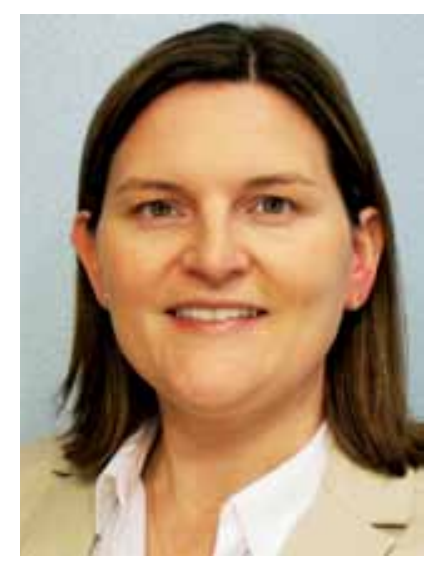

Dr. Stephanie Hansen is an Associate Professor in Beef Feedlot Nutrition at Iowa State University. She is recognized as an expert in mineral nutrition. She received early career awards from the College of Agriculture in teaching in 2014 and research in 2016, the University award for early career achievement in research in 2016, and the Midwest ASAS award for early achievement in research in 2017 . With 50 peerreviewed publications and 7.75 million in funding as Co-PI or PI she has established an original and impactful research program for beef cattle. Her research focuses on the influence of micronutrients on beef cattle performance, carcass quality and meat characteristics, improving feed efficiency of beef cattle, and assessment of novel feedstuffs. Strong collaborations and unique applications of techniques to research mineral nutrition have been critical to her success. Graduates of her program are in demand and are serving the industry. Dr. Hansen teaches courses in animal nutrition.

\section{Equine Science Award}

\section{Dr. Paul D. Siciliano North Carolina State University}

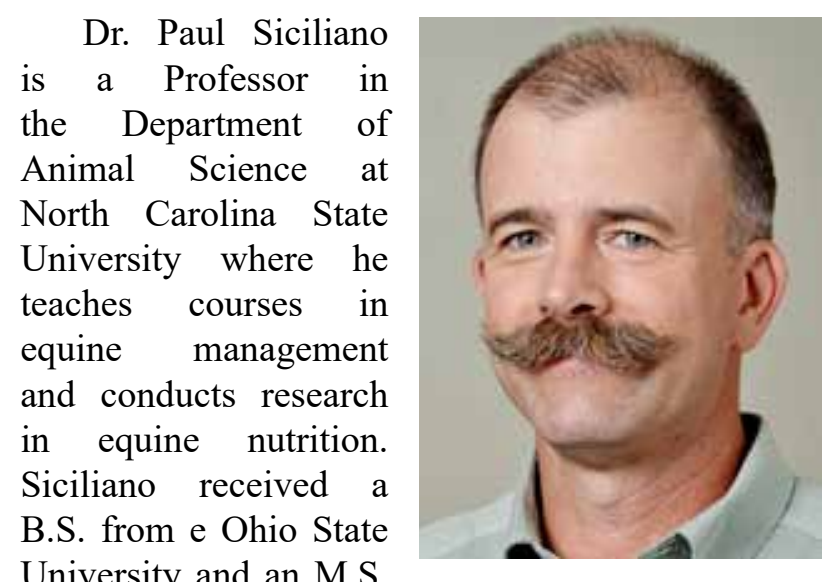


and Ph.D. from the University of Kentucky. He was a faculty member in the Department of Animal Science at Colorado State University from 1996 to 2006. He is recognized as one of the leading equine nutritionists in the US and has 53 peer-reviewed publications; obtained over \$750,000 in grants; given 147 invited presentations and trained 27 graduate students. Dr. Siciliano has been elected to numerous leadership roles by Equine Science Society membership including Past President, President, Vice President, Program Chair for the national meeting, Secretary/ Treasurer, and as a member of the Board of Directors (2000-2005). He also served as a member of the National Research Council Committee on Nutrient Requirements of Horses (2004-2007).

\section{Extension Award}

\section{Dr. John F. Patience Iowa State University}

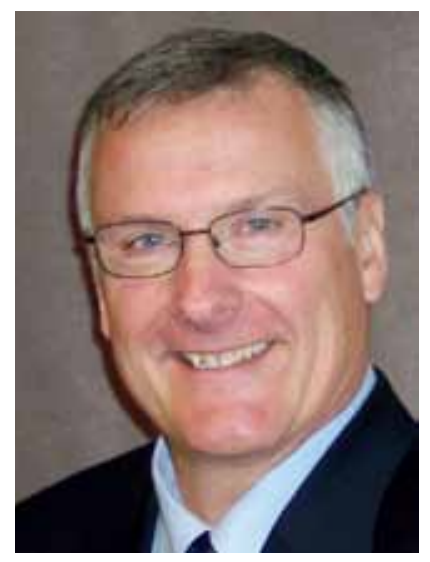

Dr. John Patience is Professor of Animal Science at Iowa State University. He earned his B.Sc. and M.Sc. degrees from the University of Guelph, and his Ph.D. from Cornell University. His extension efforts have spanned 40 years, and include establishing a new applied research and technology transfer company, initiating numerous new conferences, publishing more than 800 documents, including 115 refereed articles and 20 books and book chapters, presenting 370 talks at academic and industry conferences and recruiting more than $\$ 49$ million in gifts and contracts. He takes great pleasure in working with the pork and feed industries, finding the dynamic nature of their people energizing and inspiring. He also enjoys working with graduate students, the very people we will depend on to help meet agriculture's future challenges. A past President of the Canadian Society of Animal Science and of the Midwest Section of ASAS, he was elected a Fellow of the Canadian Society in 2010.

\section{Gary L. Cromwell Award for Minerals Nutrition \\ Dr. Xingen Lei \\ Cornell University}

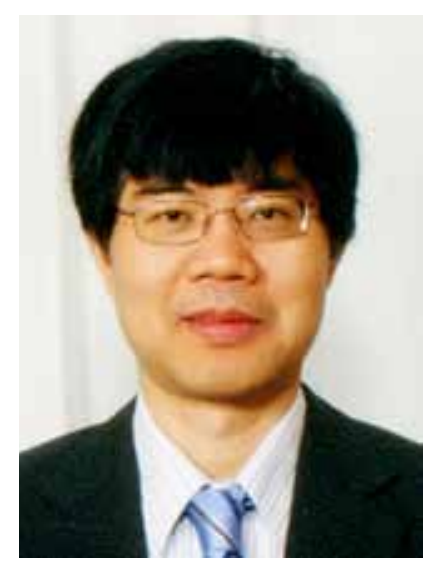

Dr. Xingen Lei received his B.S. and M.S. in China, and Ph.D. from Michigan State University. He was among the first to demonstrate nutritional and environmental values of supplemental phytase in improving feed phosphorus utilization. Lei developed a new generation of bacterial phytases that are used worldwide by the feed industry. Lei also pioneered nutritional genomics of selenium in pigs and chicks, and revealed dual roles of selenium in oxidative stress and diabetes. Lei discovered novel enhancers to improve iron nutrition of pigs. Lei authored over 400 publications, advised over 130 graduate students, postdocs, and visiting fellows, and served on panels for NIH and USDA, the NRC Committee on Mineral Toxicity, the CAST Task Force on Biotechnology and Manure Nutrients, and 9 Editorial Boards. Overall, Lei's creative research on minerals has demonstrated clear benefits to animal agriculture and the environment.

\section{H. Allen Tucker Lactation and Endocrinology Award}

\section{Dr. Rupert Bruckmaier University of Bern}

\footnotetext{
Dr. Bruckmaier has been working on the physiology and endocrinology of lactating ruminants. His work contributed significantly to the knowledge in the field of milking physiology and the importance of oxytocin and other hormones in the regula-
} 
tion of milk ejection. The work from his group also contributed significantly to understanding the mammary immune response, including pathogen-specific differences of activation of different components of the immune system, thus explaining differences in the course of mastitis after infection with different pathogens. His studies on the metabolism of high yielding dairy cows have shown an individually different adaptive capacity to metabolic load as a potential basis for animal breeding, but also a different endocrine adaptation to nutrient deficiency at different stages of lactation. During all research activities he has tried to support young scientists in the development of their future careers.

\section{H. Allen Tucker Lactation and Endocrinology Award \\ Dr. Geoffrey E. Dahl \\ University of Florida}

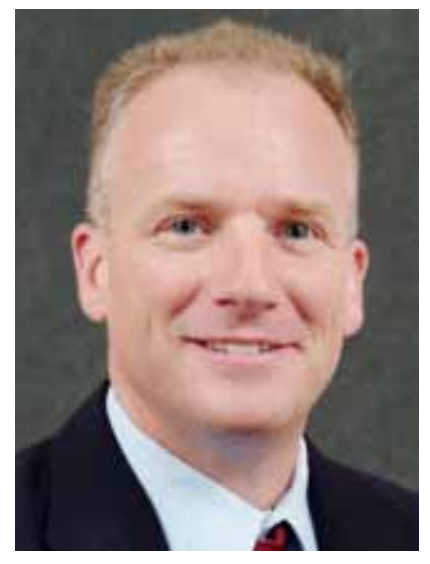

Dr. Geoffrey E. Dahl serves as Professor and Chair in the Department of Animal Sciences at the University of Florida, Gainesville. He was raised on a dairy farm in Massachusetts and pursued his B.S. in Animal Science from the University of Massachusetts, his M.S. in Dairy Science from Virginia Tech, and received his Ph.D. in Animal Science from Michigan State University. Prior to serving at the University of Florida, Dr. Dahl has held positions at the University of Michigan, University of Maryland, College Park and the University of Illinois, Urbana-Champaign. Dr. Dahl has served both ASAS and ADSA with distinction on numerous committees and through editorial work for both JAS and JDS. In addition to serving as Chair, Dr. Dahl maintains active research and outreach programs focused on environmental management of production animals, particularly dairy cattle. His specific research program includes determining effects and mechanisms of photoperiod manipulation and heat stress abatement during the dry period on cow and offspring productivity and health. He has taught at the undergraduate and graduate levels in animal science, dairy management, animal physiology, lactation physiology, endocrinology, and reproductive physiology, and received teaching and mentoring awards from the Universities of Maryland, Illinois, and Florida. To date, Dr. Dahl has authored over 105 peer-reviewed journal articles, and numerous book chapters, proceedings, and popular-press articles. He has trained 18 graduate students and 7 post-doctoral fellows.

\section{L.E. Casida Award \\ Dr. Janice M. Bahr \\ University of Illinois - Urbana-Champaign}

Dr. Janice $\mathrm{M}$. Bahr, a Wisconsin native, obtained a B.A. degree at Viterbo University, and M.S. and $\mathrm{Ph} . \mathrm{D}$. degrees at the University of Illinois at Urbana-Champaign. She accepted an assistant professorship in the Department of Animal Science at the University of Illinois in

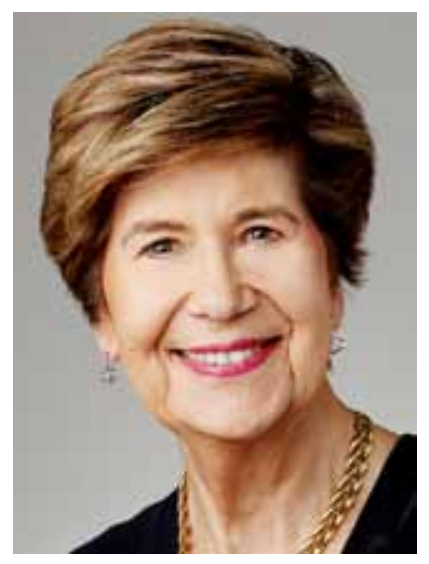
1974 where she is now professor emerita. She has 180 refereed publications, 32 book chapters, and one book. She has mentored 33 M.S. students, 27 Ph.D. students and 6 postdoctoral fellows. She has given numerous seminars at U.S. universities and at national and international conferences. She has received many awards, including several for mentoring graduate students and postdoctoral fellows. Dr. Bahr's method of mentoring was greatly influenced by her mentor, Dr. A. V. Nalbandov, who was a graduate student mentored by Dr. L. E. Casida. 


\section{Meats Research Award}

Dr. Frank R. Dunshea

University of Melbourne

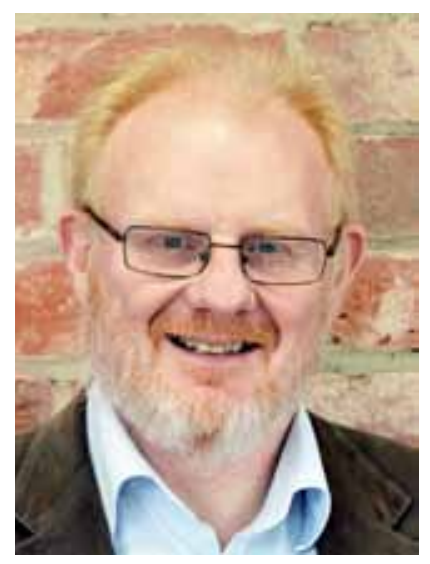

Following training at $\mathrm{La}$ Trobe and Cornell Universities, Dr. Dunshea worked as government scientist for 17 years. For the past 10 years he has been Chair of Agriculture at $\mathrm{e}$ University of Melbourne. His research on meat and carcass quality has an impressive breadth including seminal contributions on effects of metabolism modifiers on meat quality. He led the commercialization of an immunocastration vaccine and conducted research on the impact of immunocastration on pork quality. A recent focus has been the development of a pork eating quality model to ensure high and consistent eating quality. Dunshea also investigated nutritional means of manipulating growth and pork quality, including the use of dietary polyenylphosphatidylcholine to reduce collagen synthesis and reduce chewiness. Overall, Dunshea's research in carcass and meat quality has lead to exciting findings, many of which have been adopted by the livestock industries.

\section{Morrison Award}

Dr. Ronnie D. Greene University of Nebraska-Lincoln

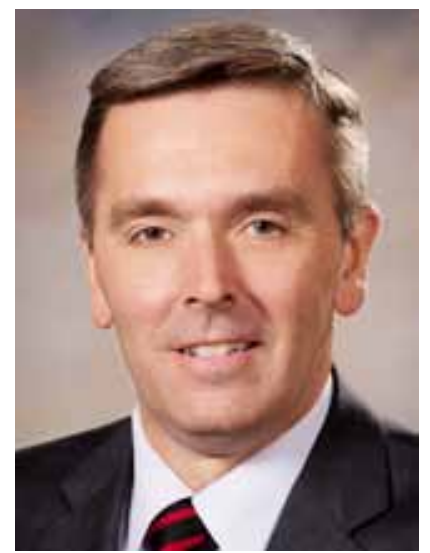

Dr. Green currently serves as the 20th Chancellor of the University of Nebraska- Lincoln. He received B.S. and M.S. degrees in animal science from Virginia Tech and Colorado State University, respectively. He completed a doctoral program jointly at the University of Nebraska and the USDA-ARS U.S. Meat Animal Research Center in animal breeding and genetics. Dr. Green previously served on the animal science faculties of Texas Tech University and Colorado State University. He has also served as national program leader for animal production research for USDA-ARS and as executive secretary of the White House's working group on animal genomics, where he facilitated the international bovine, porcine, and ovine genome sequencing projects. He also served as senior global director for Pfizer Animal Health's animal genetics business. Dr. Green is author of over 130 refereed journal papers and abstracts, nine book chapters and 56 symposia papers, and has spoken in 43 U.S. states and 21 countries around the world. Dr. Green and his wife Jane are the proud parents of sons Justin and Nate, daughters Kelli and Regan and one granddaughter, Charlotte.

\section{Rockefeller Prentice Award in Animal Breeding and Genetics \\ Dr. Archie C. Clutter University of Nebraska-Lincoln}

Dr. Archie C. Clutter is Dean of the Agricultural Research Division at the University of Nebraska, and Director of the Nebraska Agricultural Experiment Station. Dr. Clutter has served as Vice President of R\&D at Newsham Choice Genetics, as Director of Swine Research at Monsanto,

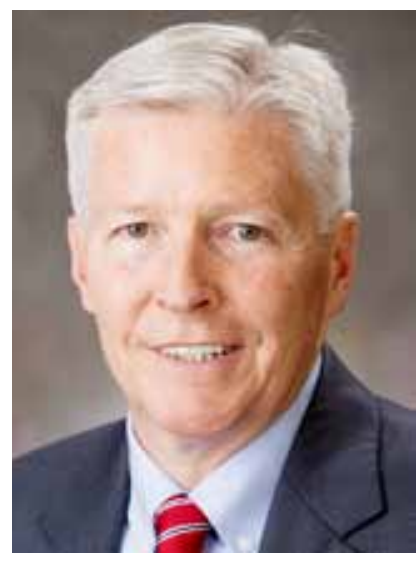
and was a Professor of

Animal Science at Oklahoma State University. He has a B.S. in Agricultural Business from Iowa State University, M.S. and Ph.D. degrees in Animal Breeding and Genetics from the University of Nebraska, and postdoc training from Iowa State University. Dr. Clutter's research has encompassed transdisciplinary studies of genomic, physiological and behavioral components underlying complex quantitative traits. These studies have included species ranging from laboratory mice to swine, and both beef and dairy cattle. In midcareer, Dr. Clutter transitioned his research from academia to industry and the application of molecular and 
conventional breeding techniques to improvement of commercial lines of pigs and chickens. e research and breeding aims of his commercial work included lean growth efficiency, meat quality, lifetime performance, and disease tolerance.

\section{Wilson G. Pond International Travel Award \\ Matthew Crouse North Dakota State University}

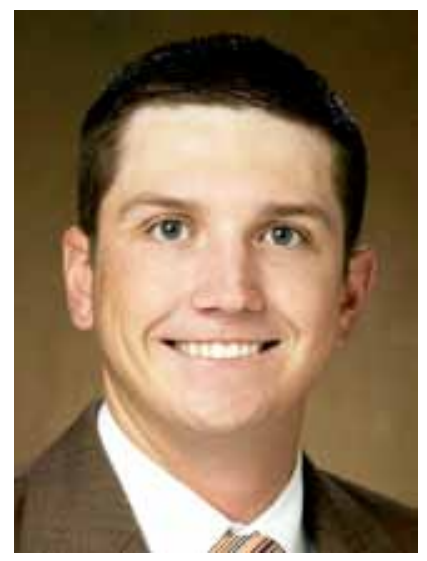

Matthew Crouse is from El Paso, TX. He received his B.S. in Animal Science with an Equine emphasis and a minor in Chemistry from New Mexico State University in 2014. As an undergraduate, he was involved in research projects with Dr. Laura White and Dr. Shanna Ivey studying glucose flux and insulin resistance in mature vs. senior horses, which stimulated an interest in his own research in an animal science graduate program. Matthew then pursued his M.S. in ruminant nutrition at North Dakota State University under the direction of Dr. Joel Caton while simultaneously fulfilling a $3 / 4$ time appointment as a technician in the NDSU nutrition laboratory. His M.S. focused on the effects of maternal nutritional status on nutrient transport expression and nutrient supply to bovine uteroplacental tissues during the first 50 days of gestation. Matthew is currently pursuing a Ph.D. at NDSU under the direction of both Drs. Joel Caton and Alison Ward. His research focuses on the effects of aberrant mat

\section{Wilson G. Pond International Travel Award}

\section{Ananda Fontoura North Dakota State University}

Ananda Fontoura is from Belém, Brazil. In 2015, she received a DVM degree at the Federal University of Pará, in Castanhal, Brazil. During her Veterinary Medicine program, she was involved in research projects concerning the biological basis of feed efficiency in beef cattle

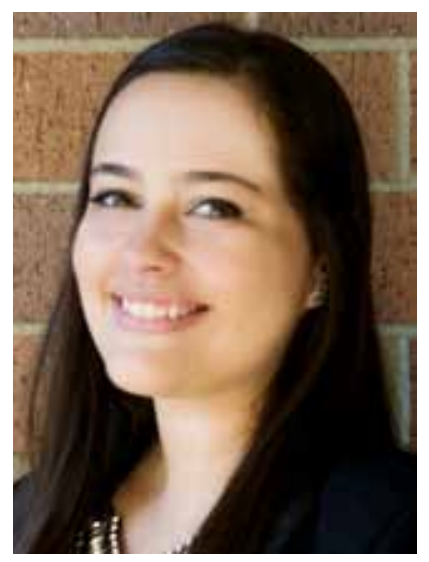
and worked under the guidance of Dr. Steve Miller at the University of Guelph, Guelph, Canada and Dr. Yuri Montanholi at Dalhousie University, Truro, Canada. This international experience at an early stage of her academic career stimulated her interest in the realities of different agricultural production systems and the challenges faced by the livestock sector. She is currently completing a MS degree in Ruminant Nutrition at North Dakota State University under the supervision of Dr. Kendall Swanson. Her MS research focuses on the biological associations between feeding behavior, linear body measurements, blood metabolites and different measures of efficiency of energy use in beef cattle.

\section{Wilson G. Pond International Travel Award}

Diego Navarro

University of Illinois - Urbana-Champaign

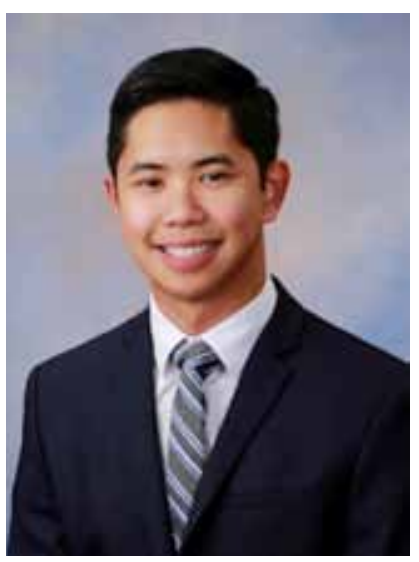

Diego Mario David L. Navarro is a $\mathrm{PhD}$ student in the Stein Monogastric Nutrition Laboratory at the University of Illinois, where he works under the guidance of Dr. Hans H. Stein. He is from the Philippines and received a $\mathrm{BS}$ in Agriculture from the 
University of the Philippines at Los Baños. He moved to Illinois in 2012 and earned a MS in Swine Nutrition from the University of Illinois in 2014 after working on amino acid and energy digestibility in feed ingredients. Diego's research towards his $\mathrm{PhD}$ degree is focused on determining the correlation between the physicochemical characteristics and energetic value of dietary fiber in feed ingredients included in swine diets. He has a number of scientific publications from his the research he has conducted towards his $\mathrm{MS}$ and $\mathrm{PhD}$ degrees at the University of Illinois. After obtaining his $\mathrm{PhD}$ degree later this year, Diego plans to return to the Philippines and work in the feed industry.

\section{Wilson G. Pond International Travel Award}

\section{Alison Ward North Dakota State University}

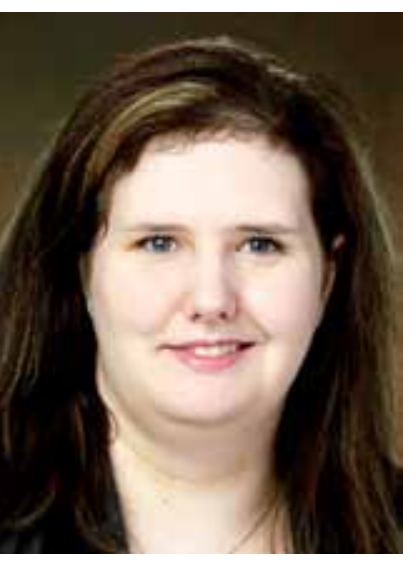

Dr. Alison Ward grew up in Saskatoon, Saskatchewan, Canada. She obtained her B.S. in 2006, M.S. in 2008, and Ph.D. in 2011 from the University of Saskatchewan. Her graduate work focused on dietary and genetic interactions in livestock: first in relation to fishyegg taint and canola meal in laying hens, and then investigating the role of the vitamin A pathway in marbling in beef cattle. In her postdoctoral fellowship with the Saskatchewan Cancer Agency, Dr. Ward studied the epigenetic silencing of a metastasis-repressor gene in human breast cancer. In July, 2015, Dr. Ward began her position as Assistant Professor, Nutritional Epigenetics in the Department of Animal Sciences at North Dakota State University. Her research interests include the role of maternal nutrition on developmental programming and the epigenome as well as continuing her work studying the nutrigenomic effect of vitamin A on intramuscular fat deposition in cattle.

\section{Joseph P. Fonetenot Appreciation Club Graduate Student Travel Scholarship}

\author{
Erin Deters \\ Iowa State University
}

\section{Evan Knutson \\ North Dakota State University}

Lyndsey Ratcliffe Athlone Institute of Technology
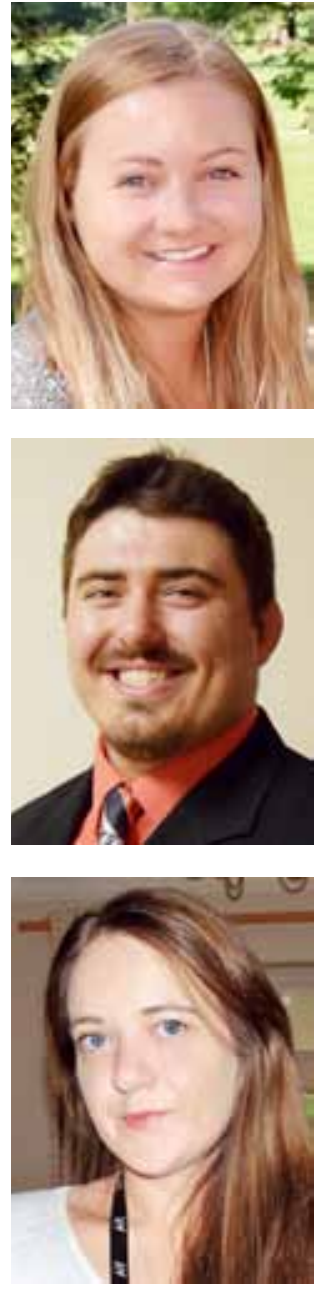